\title{
Fake News and the Economy of Emotions
}

\author{
Bakir, Vian; McStay, Andrew
}

\section{Digital Journalism}

\author{
DOI: \\ 10.1080/21670811.2017.1345645
}

Published: 01/01/2018

Peer reviewed version

Cyswllt i'r cyhoeddiad / Link to publication

Dyfyniad o'r fersiwn a gyhoeddwyd / Citation for published version (APA):

Bakir, V., \& McStay, A. (2018). Fake News and the Economy of Emotions: Problems, Causes, Solutions. Digital Journalism, 6(2), 154-175. https://doi.org/10.1080/21670811.2017.1345645

\footnotetext{
Hawliau Cyffredinol / General rights

Copyright and moral rights for the publications made accessible in the public portal are retained by the authors and/or other copyright owners and it is a condition of accessing publications that users recognise and abide by the legal requirements associated with these rights.

- Users may download and print one copy of any publication from the public portal for the purpose of private study or research.

- You may not further distribute the material or use it for any profit-making activity or commercial gain

- You may freely distribute the URL identifying the publication in the public portal ?
}

Take down policy

If you believe that this document breaches copyright please contact us providing details, and we will remove access to the work immediately and investigate your claim. 


\title{
Fake News and the Economy of Emotions: Problems, Causes, Solutions
}

\author{
Vian Bakir and Andrew McStay
}

\begin{abstract}
This paper examines the 2016 US presidential election campaign to identify problems with, causes of, and solutions to, the contemporary fake news phenomenon. To do this we employ textual analysis and feedback from engagement, meetings and panels with technologists, journalists, editors, non-profits, public relations firms, analytics firms and academics during the globally-leading technology conference, South-by-South West, in March 2017. We further argue that what is most significant about the contemporary fake news furore is what it portends: the use of personally and emotionally targeted news produced by algo-journalism and what we term 'empathic media'. In assessing solutions to this democratically problematic situation, we recommend that greater attention be paid to the role of digital advertising in causing, and combating both the contemporary fake news phenomenon, and the near-horizon variant of empathically-optimised automated fake news.
\end{abstract}

Keywords: digital advertising, emotion, Facebook, fake news, Trump election, empathic media

\section{Introduction}

We analyse the contemporary fake news phenomenon that emerged during the 2016 US presidential election campaign battle between Donald Trump and Hillary Clinton, as proTrump fake news stories spread across Facebook. Definitions of fake news abound, including "propaganda entertainment" (Khaldarova and Pantti 2016, 893); "using satire to discuss public affairs" (Marchi 2012, 253); and content that "blurs lines between nonfiction and fiction" (Berkowitz and Schwartz 2016, 4). More comprehensively, Wardle (2017) deconstructs fake news into seven categories: false connection (where headlines, visuals or captions do not support the content); false context (genuine content shared with false contextual information); manipulated content (genuine imagery/information manipulated to deceive); misleading content (misleading use of information to frame an issue or individual); imposter content (genuine sources are impersonated); fabricated content (100\% false, designed to deceive and harm); and satire/parody (with potential to fool but no intention to cause harm) (Wardle 2017). Distilling Wardle's (2017) typology, we define fake news as either wholly false or containing deliberately misleading elements incorporated within its content or context. A core feature of contemporary fake news is that it is widely circulated online (Bounegru et al. 2017, 8) where people accept as fact "stories of uncertain provenance or accuracy" (Culture, Media and Sport Committee 2017).

We begin by assessing social and democratic problems with contemporary fake news, and proceed to examine solutions offered by companies such as Facebook. We argue that, at heart, the fake news problem concerns the economics of emotion: specifically, how emotions are leveraged to generate attention and viewing time, which converts to advertising revenue. We further point out the economic and political incentives to produce automated fake news that reacts to what we term online "fellow-feeling", or group emotional behaviour within social networks. The capacity to better understand feelings, moods and emotions in networked communication is rapidly increasing through adoption of online and biofeedback technologies that pertain to record and assess our emotions - what McStay (2016b) terms "empathic media". This catchall term reflects an overall rise of interest in mediated emotional life, which is gauged by a range of technologies for a number of purposes. Technologies 
include facial coding, voice analytics, virtual reality, augmented reality, wearables, biosensors and sentiment analysis. By making emotions machine-readable these can be employed to enhance peoples' relationships with devices and content, but there is also increased capacity to influence (McStay 2016b, 2017, 2018 forthcoming). Of greatest relevance to the fake news issue is analysis of emotions in words and images (sentiment analysis). We suggest that the potential to manipulate public sentiment via empathically-optimised automated fake news is a near-horizon problem that could rapidly dwarf the contemporary fake news problem. We conclude that more attention should be paid to the role of digital advertising, both in causing, and combating contemporary and near-horizon fake news phenomena.

\section{Methods}

Our case study is the contemporary fake news phenomenon that emerged during the 2016 US presidential election campaign. Its seeds were laid in 2010 when Facebook introduced its newsfeed algorithm, Edgerank. This has since evolved into a machine-learning algorithm that prioritises and presents content to users based on factors including what they have engaged with (likes/reactions, comments, shares, views, clicks and pauses), what groups they belong to, and the type of content Facebook is currently prioritising. In 2016, populist, mostly pro-Trump fake news stories spread across Facebook, often generating more audience engagement than real news stories (Silverman 2016), creating consternation that Facebook and fake news may have influenced the election's outcome. This prompted Facebook, other telecommunications platforms, legacy and digital news outlets and agencies, and non-profit organisations to find solutions to combat fake news. In January 2017, the UK Parliament's Culture, Media and Sport Committee launched its Fake News Inquiry to identify best solutions. ${ }^{1}$ In April 2017, Germany's government planned to legislate for fines of up to 50 million Euros if social media networks refuse to remove fake news, hate speech and other illegal content. As such, this is a politically and socially important case study, with numerous implications for democratic health (outlined later).

Trump's election win confounded most pollsters and mainstream journalists, but analytics company Ezyinsights predicted the win from the Trump's campaign's Facebook engagement (El-Sharawy 2016). Through qualitative, thematic textual analysis, we glean insights into the content that engaged Facebook users, using this to help us diagnose what is socially and democratically problematic about contemporary fake news. We focus on captioned images popular on the Facebook page of far-right American news, opinion and commentary website, Breitbart. These are significant to examine for various reasons. Firstly, analysis from EzyInsights of social media engagement for the nine months prior to the US presidential election (February to October 2016) shows that for almost this entire period, Trump generated much more Facebook engagement than Clinton. EzyInsights shows that the Facebook engagement resulted from Trump's campaign emphasising video and captioned images at specific moments when their audience was ready to engage (El-Sharawy 2016). Secondly, according to EzyInsights, Breitbart generated high user engagement on Facebookas much as the Huffington Post - with Breitbart's captioned images generating the most engagement across August to October 2016 (El-Sharawy 2017). EzyInsights' study, however, does not delve into their content.

Addressing this gap, our sample comprises all Breitbart captioned images archived in Breitbart's Facebook Timeline Photos in the five weeks prior to the US presidential election (1 October to 7 November 2016) - a total of 75 images. ${ }^{2}$ Using a data-first approach (Miles, Huberman, and Saldana 2014), we thematically code each image to identify its key message, noting the caption, visual image, and Breitbart's accompanying comment and hashtag on Facebook. We found that the emergent themes frequently focused on the candidates' personalities, the news media, the voters and policy issues. While the captioned images merit 
a separate paper to delve into their rich semiotic and multi-modal construction, due to reasons of space we summarise our qualitative findings with a table that illustrates commonly occurring themes (five occurrences or more) (Table 1). Given our paper's focus, we were particularly alert to whether these themes (1) contribute to the fake news discourse; and (2) stimulate and affectively engage audiences - these aspects are discussed in a later section on social and democratic problems.

Table 1 Main repeated themes in Breitbart's Facebook Timeline Photos (1 Oct. - 7 Nov. 2016)

\begin{tabular}{|c|c|c|}
\hline Theme & Example & $\begin{array}{l}\text { No. of } \\
\text { images }\end{array}$ \\
\hline \multicolumn{3}{|c|}{ About Candidates' Personality } \\
\hline $\begin{array}{l}\text { Hillary Clinton is } \\
\text { crooked \& corrupt }\end{array}$ & $\begin{array}{l}\text { The caption in red is, "Sec of State Hillary Clinton approved the } \\
\text { transfer of } 20 \% \text { of US uranium to Putin's Russia as } 9 \text { investors } \\
\text { in the deal funneled [sic] } \$ 145 \text { million to the Clinton } \\
\text { Foundation. NYT \& Clinton Cash". The largely black image } \\
\text { behind the caption is a head-and-shoulder shot of a silhouette of } \\
\text { a woman's head (20 Oct.) }\end{array}$ & 16 \\
\hline Trump is a winner & $\begin{array}{l}\text { The caption in black letters, "Trump wins stunning debate } \\
\text { victory!" is against a backdrop of the US flag. In front of this is a } \\
\text { three-quarters shot of Trump, applauding (10 Oct.) }\end{array}$ & 6 \\
\hline \multicolumn{3}{|c|}{ About News Media } \\
\hline $\begin{array}{l}\text { Establishment } \\
\text { media are rigged in } \\
\text { favour of Clinton }\end{array}$ & $\begin{array}{l}\text { The caption, "Establishment media are Hillary Clinton campaign } \\
\text { workers", is in yellow lettering against a purple background, } \\
\text { accompanied by Breitbart's hashtag, "\#rigged" (16 Oct.) }\end{array}$ & 6 \\
\hline $\begin{array}{l}\text { Promoting } \\
\text { Breitbart }\end{array}$ & $\begin{array}{l}\text { The caption in white is "battle gear" above a photo of pro-Trump } \\
\text { campaigning products (a baseball cap, T- shirts and mug) each } \\
\text { displaying Breitbart's logo or product colors (16 Oct.) }\end{array}$ & 5 \\
\hline \multicolumn{3}{|c|}{ About Voters } \\
\hline $\begin{array}{l}\text { Clinton thinks } \\
\text { Trump voters are } \\
\text { 'deplorable' }\end{array}$ & $\begin{array}{c}\text { The caption, "Hillary thinks you're deplorable. The media } \\
\text { think's you're stupid" floats above a photo of an old man } \\
\text { wearing a US Marines T-shirt and holding up a "Trump/Pence - } \\
\text { Make America Great Again" poster (10 Oct.) }\end{array}$ & 5 \\
\hline $\begin{array}{l}\text { Urging Trump } \\
\text { voters to vote }\end{array}$ & $\begin{array}{c}\text { The yellow-lettered caption, "Let's roll, deplorables", is against } \\
\text { a backdrop of Trump speaking at a podium ( } 28 \text { Oct.) }\end{array}$ & 5 \\
\hline \multicolumn{3}{|c|}{ About Policy Issues } \\
\hline $\begin{array}{l}\text { Trump will end } \\
\text { political corruption } \\
\& \text { protect jobs/ } \\
\text { national security }\end{array}$ & $\begin{array}{l}\text { The caption, "It's time to drain the swamp", appears in yellow- } \\
\text { highlighted black capitals, over a mid-shot of Trump speaking at } \\
\text { the podium, accompanied by Breitbart's hashtags, } \\
\text { "\#Debate2016 \#DrainTheSwamp" (20 Oct.) }\end{array}$ & 5 \\
\hline
\end{tabular}

We enrich our case study with conversations with technologists, journalists, editors and analytics firms conducted across seven days in March during the Interactive portion of the 2017 South-by-South West (SXSW) event. This globally-renowned, annual technology conference, trade fair and festival presents cutting edge practices and ideas capable of transforming the future of entertainment, culture and technology. Through 17 hour-long interactive panel and solo sessions from journalism, marketing, government and the technology industry, we asked questions, debated and ascertained current thinking and practice among a wide range of interested parties to the contemporary fake news phenomenon (see Table 2). 
Table 2 Organisations Discussing Fake News Phenomenon at SXSW (2017)

\begin{tabular}{|l|l|}
\hline Type of Organisation & Organisation \\
\hline $\begin{array}{l}\text { Legacy news outlets -regional } \\
\text { (USA) }\end{array}$ & $\begin{array}{l}\text { Austin American-Statesman } \\
\text { The Texas Tribune } \\
\text { The Dallas Morning News }\end{array}$ \\
\hline $\begin{array}{l}\text { Legacy news outlets -national } \\
\text { (USA) }\end{array}$ & $\begin{array}{l}\text { The Washington Post } \\
\text { The New York Times }\end{array}$ \\
\hline News agencies (USA/Norway) & $\begin{array}{l}\text { Associated Press } \\
\text { Norwegian News Agency }\end{array}$ \\
\hline Online news curator (USA) & NextDraft \\
\hline $\begin{array}{l}\text { Online news aggregator/web } \\
\text { content rater/discussion website } \\
\text { (USA) }\end{array}$ & $\begin{array}{l}\text { Reddit } \\
\text { The Huffington Post }\end{array}$ \\
\hline $\begin{array}{l}\text { Non-profit organisations } \\
\text { (USA/UK) }\end{array}$ & $\begin{array}{l}\text { First Draft: finds solutions to trust and truth challenges in } \\
\text { digital age; } \\
\text { PolitiFact: fact-checker } \\
\text { Full Fact: fact-checker } \\
\text { International Fact-Checking Network/Poynter Institute: } \\
\text { journalism educator and fact-checker }\end{array}$ \\
\hline $\begin{array}{l}\text { PR/media/communications } \\
\text { agencies (USA/UK) }\end{array}$ & $\begin{array}{l}\text { freuds } \\
\text { Arrow Media } \\
\text { Razorfish }\end{array}$ \\
\hline $\begin{array}{l}\text { Technology companies (USA, } \\
\text { Finland) }\end{array}$ & $\begin{array}{l}\text { EzyInsights: provides content discovery and news tracking } \\
\text { service } \\
\text { Countable: provides mobile and web-based app enabling } \\
\text { people to review upcoming legislation in US Congress and } \\
\text { express views } \\
\text { Automated Insights: provides readable narratives from } \\
\text { analysing big data patterns }\end{array}$ \\
$\begin{array}{l}\text { Duke University } \\
\text { Vanderbilt University } \\
\text { American University } \\
\text { The University of Texas at Arlington }\end{array}$ \\
\hline Academic
\end{tabular}

\section{Fake News: Historical and Contemporary Context}

Today's fake news furore must be seen against the backdrop of long-standing, systematic, political and commercial efforts in liberal democracies to persuade and influence populations through propaganda (Jowett and O'Donnell 2012), Public Relations (PR) (Moloney 2006), political marketing (Scammell 2014) and spin (Miller and Dinan 2008). News media are often a focus of persuasion and influence efforts, given their professional commitment to accuracy, facticity, and in some cases impartiality and objectivity. Thus, information imparted via news (or what looks like news) confers credibility and truth to the content. The 20th and 21st centuries have seen PR firms spinning, or sometimes wholly fabricating, news stories for their clients (Miller and Dinan 2008, Leveson Inquiry 2012). Whether for economic or political gain, fake news in some form has long been with us, the product of professional persuaders. However, the digital media ecology has proliferated, democratised and intensified the scale of fake news. We argue, below, that the contemporary fake news phenomenon is a logical outcome of five features of the digital media ecology: the financial decline of legacy news; the news cycle's increasing immediacy; the rapid circulation 
of misinformation and disinformation via user-generated content and propagandists; the increasingly emotionalised nature of online discourse; and the growing number of people financially capitalising on algorithms used by social media platforms and internet search engines.

Firstly, journalism has suffered from declining paying audiences, and hence revenue, for over a decade. Audiences have become disloyal to legacy news brands, and less willing to pay for news given the proliferation of free news online (Reuters Institute 2016). Shrinking paying news audiences reduces revenue from cover prices and from advertisers. While total digital advertising spending has grown in recent years, legacy news organisations have not benefitted. Rather, most digital advertising revenue (65\% in 2015) goes to five technology companies - four of which (Facebook, Google, Yahoo and Twitter) integrate news into their offerings (Pew Research Center 2016). As legacy news outlets have struggled to profit across the past decade, they have been closing and reducing staff (Pew Research Center 2016, McStay 2016a).

The second feature of digital media culture favouring fake news is the drive for immediacy: the 24-hour news cycle is better phrased the 1,440-minute news cycle (Gillmor 2009) given the advent of social media outlets like Twitter (which since 2016, self-branded as a breaking news platform). These factors mean that scarce journalistic resources are spread thinner, mitigating against time-consuming, fact-checking journalism. This increases the press' susceptibility to using unchecked PR material, and 'editorial subsidies' where PR practitioners go beyond providing information subsidies (facts, statistics or quotes) to providing stories' editorial framing (Jackson and Moloney 2016).

A third feature of the digital media ecology is the increasing amount of (1) misinformation (inadvertent online sharing of false information) and (2) disinformation (deliberate creation and sharing of information known to be false) rapidly circulating via usergenerated content and propagandists. While academic and journalistic attention to fake news and disinformation is ongoing, especially its seeding by Russian news/propaganda outlets (Khaldarova and Pantti, 2016; Ackerman 2017), misinformation is rarely examined (although see Wardle 2017).

A fourth feature of contemporary media is that it is increasingly emotionalised (Richards 2007). This is especially so online, as, for various reasons, including anonymity, people are less inhibited online (see Suler's (2016) 'online disinhibition effect'). This is fertile ground for the rise of targeted media content and news contexts (such as filter bubbles in the form of Facebook news feeds) that elicit affective reactions.

A fifth feature of the contemporary digital media ecology is the growing number of people profiting from online behavioural advertising. For them, fake news acts as clickbait namely, web content designed to generate attention and online advertising revenue at the expense of quality or accuracy, relying on sensationalist headlines or eye-catching pictures to attract click-throughs and shares. Journalists traced a significant amount of the fake news upsurge on Facebook during the 2016 US presidential election campaign to computer science undergraduates and teenagers in Veles, Macedonia who launched multiple US politics websites (estimates range from dozens to 140) with American-sounding domain names like USADailyPolitics.com, WorldPoliticus.com and DonaldTrumpNews.co (Kirby 2016, Silverman and Alexander 2016; Gillin 2017). The fake news stories generated large, engaged audiences, earning some students thousands of Euros daily through digital advertising (Kirby 2016). Most of the Veles locals created fake news stories for money rather than propaganda (Tynan 2016): their experiments with left-leaning content simply under-performed compared to pro-Trump content on Facebook. Other profit-oriented fake news genres also proliferate, including health and well-being sites (Silverman and Alexander 2016); and sites where US celebrities praise a small, US town for its helpful people and promising blockbusters filming 
nearby, apparently micro-targeting these town residents to gain advertising clicks (Gillin 2017).

\section{Contemporary Fake News: Social and Democratic Problems}

The fake news situation is socially and democratically problematic on three fronts: (1) its production of wrongly informed citizens, that (2) are likely to stay wrongly informed in echo chambers and (3) be emotionally antagonised or outraged given the affective and provocative nature of much fake news. These are discussed below, and illustrated by our analysis of frequent themes in Breitbart's Facebook Timeline Photos (see Table 1).

\section{Wrongly informed Citizens}

That fake news makes citizens less well informed is obvious, but worth stating given that well informed citizens are vital to democracy. Fears were expressed that fake news may have influenced the 2016 US presidential election's outcome. For instance, in the election campaign's final three months, the most engaged-with story was 'Pope Francis Shocks World, Endorses Donald Trump for President, Releases Statement', this 100\% fabricated story amassing 960,000 Facebook shares, likes and comments (Price 2016; Silverman 2016). Although one study concludes that, for fake news to have changed the election's outcome, a single fake article would need to have been as persuasive as 36 television campaign advertisements (Allcott and Gentzkow 2017), such was the level of public concern that, two days after the election, Facebook's Chief Executive Officer (CEO), Mark Zuckerberg, felt compelled to publically rebut the charge that fake news on Facebook influenced the election. However, his position rapidly changed, as we show later.

Even if fake news did not influence the election, widespread recirculation of falsehoods posing as news does not bode well for the factual foundations on which citizens form opinions, and the nation's consequent democratic health. While some fake news stories are recognisable as satire (Berkowitz and Schwartz 2016), others are variants of well-known news brands, and more difficult to recognise as fake. For those who think they can always recognise fake news, it would be instructive to play human computation game Factitious $^{3}$ (Game Lab, Jolt), which challenges players to quickly identify true or false articles from news, advertising, opinion or fake (Datu et al. 2017). Certainly, a study by Stanford History Education Group (2016: 4) of 7,800 responses from US middle school, high school and college students on their ability to assess online information sources concludes that they 'are easily duped'.

Our analysis of Breitbart's Facebook Timeline Photos for the five weeks prior to the US election confirms their use of disinformation. With 16 images, the most frequent theme is that Hillary Clinton is crooked and corrupt (21\% of the 75 images) (see Table 1). One variant of this theme focuses on the Clinton Foundation, a charitable organisation aiming to improve human life globally. For instance, a head-and-shoulder shot of a silhouette of a woman's head is captioned, "Sec of State Hillary Clinton approved the transfer of $20 \%$ of US uranium to Putin's Russia as 9 investors in the deal funneled [sic] \$145 million to the Clinton Foundation. NYT \& Clinton Cash" (Breitbart 2016c). We classify such statements as deliberately misleading as Breitbart's charges of corruption are unsupported by facts. For instance, in April 2016, rating group Charity Watch (2016) reported that $88 \%$ of the money the Clinton Foundation raises goes to its programmes (the rest spent on overheads), surpassing the $75 \%$ benchmark for reputable charity groups. Furthermore, despite Schweizer's (2015) book, Clinton Cash (cited in the poster), listing numerous examples of Clinton Foundation donations that were followed by State Department actions favourable to the donor, Obama's US Justice Department concluded there were no grounds for a formal investigation. 


\section{Echo Chambers: Staying Wrongly Informed}

The second social and democratic problem with fake news is that it goes uncorrected, leading citizens to stay wrongly informed. This happens because the false information is fed into self-reinforcing algorithmic and cognitive systems, or digital 'echo chambers'. Echo chambers exist where information, ideas or beliefs are amplified and reinforced by communication and repetition inside a defined system where competing views are underrepresented (Sunstein 2001). Algorithmically-created echo chambers, or 'filter bubbles', arise when algorithms applied to online content selectively gauge what information a user wants to see based on information about the user, their connections, browsing history, purchases, and what they post and search. This results in users becoming separated from exposure to wider information that disagrees with their views (Pariser 2011). A closely related psychological phenomenon is 'confirmation bias', or people's tendency to search for, interpret, notice, recall and believe information that confirms their pre-existing beliefs (Wason 1960). Empirically demonstrated consequences of algorithmically created filter bubbles and human confirmation bias are limited exposure to, and lack of engagement with, different ideas and other people's viewpoints (Bessi et al. 2016; Quattrociocchi et al. 2016). This may occur without people even being aware of the process: for instance, US college students are largely unaware of how gatekeepers of news sources that use personalisation algorithms (Google and Facebook) track user data and apply editorial judgements to deliver personalised results (Powers 2017).

El-Sharawy (2017) explains from his company's study of Facebook engagement in the 2016 US presidential election that Trump's campaign team encouraged the two opposing filter bubbles that developed on Facebook: prominence of very right-wing versus mainstream media in users' newsfeeds. This is backed up by our own analysis of Breitbart's Facebook Timeline Photos which shows that they repeatedly slurred mainstream media as 'rigged' in favour of Clinton (six images): for instance, 'Establishment media are Hillary Clinton campaign workers', accompanied by “\#rigged” (Breitbart 2016b). Breitbart also repeatedly promoted its own news brand on Facebook with product shots of its logo and office (five images) (see Table 1). Together, these themes encourage readers to disbelieve mainstream media and remain in their Breitbart filter bubble.

It was not just US citizens experiencing filter bubbles, but also journalists. As ElSharawy (2017) describes: "In the run up to the US presidential election, we said right-wing sites were doing well. We told people to look at it, but mainstream media weren't keen." One reason he posits for lack of interest is mainstream journalists' own filter bubble. For instance, journalists favour using Twitter over Facebook (Reuters Institute 2016), but in the run-up to the 2016 election, EzyInsights found that fake news and right-wing websites had a much smaller reach, and hence visibility, on Twitter than on Facebook (El-Sharawy 2017).

\section{Affective Content}

The third social and democratic problem with fake news is that it is often deliberately affective. As El-Sharawy (2017) states, "Facebook favours emotional content that hits people whether or not it is true". Our analysis of Breitbart's Facebook Timeline Photos confirms their affective content designed to provoke voter outrage. This is directly evident in the themes about voters (see Table 1). One theme is that Clinton thinks that Trump voters are "deplorable" (5 images) - a rehash of Clinton's September 2016 use of the phrase "basket of deplorables" to describe half of Trump's supporters. For instance, one image portrays an old man in a US marines T-shirt, holding a Trump/Pence poster, the image captioned, "Hillary thinks you're deplorable The media thinks you're stupid" (Breitbart 2016a). Another five images affectively urge Trump voters to vote. For instance, incorporating Clinton's 
"deplorables" insult, one poster depicts Trump speaking at a podium, captioned, "Let's roll, deplorables" (Breitbart 2016e).

Looking at the most common themes within the 75 Breitbart Facebook images, rather than focusing on policies, the most frequent themes focus on the candidates' personality, with 16 captioned images attacking Clinton's personality as crooked and corrupt; and another six images portraying Trump as a winner (see Table 1). Where policies are presented, these are as simplistic end goals and claims. For instance, Trump's anti-corruption policy is presented by an image of Trump speaking at the podium, captioned, "It's time to drain the swamp" (Breitbart 2016d).

If fake news circulates, uncorrected, in closed communities; if people are indoctrinated to disbelieve truthful facts by damaging the reputation of mainstream news; and if that fake news is deliberately affective and inflammatory, we are moved ever further from Habermas' archetypal democratic ideal of a public sphere that ultimately seeks consensus through enabling all to speak rationally, through listening to others' viewpoints and agreeing the best way forward (Habermas 1984). Even if one rejects such idealism, adopting a position closer to Mouffe's (2005) framework of agonistic pluralism, with winners and losers in a potentially emotional, identity-based political struggle and debate, if losers lose based on what they perceive to be the winners' false claims, then ensuing social discontent with the democratic outcome and process is likely. The logical end result is highly polarised societies, losers' decreased confidence in government's legitimacy, and inappropriate democratic decisions taken based on affective misinformation and disinformation.

\section{Proposed Solutions}

As The Guardian noted on 11 November 2016, the initial reaction of Facebook's CEO, Mark Zuckerberg, to the fake news furore was to declare Facebook's impact on the presidential election as minimal, also rejecting the idea of filter bubbles on Facebook users' news feeds as "most users have friends who have different political views to their own". For Zuckerberg, Facebook's core problem was getting people to engage with the diverse content available to them: lack of engagement was problematic because the less that people engage with content, the less likely their newsfeed would surface it. What Facebook did not want, however, was to become "arbiters of truth ourselves", because it believes in "giving people a voice, which means erring on the side of letting people share what they want whenever possible" (Zuckerberg 2016b). Instead, Facebook preferred to "find ways for our community to tell us what content is most meaningful" (Zuckerberg 2016a). However, within 11 days of the US presidential election, Facebook's position changed from declaring that Facebook's impact was minimal, to specifying how it planned to combat fake news. Unusually, it revealed features under-construction comprising: elevating the quality of "related articles" in the news feed; third-party verification by fact-checking organisations; stronger technical detection of misinformation; easier user reporting of fake news; warning labels on stories flagged as false; "Listening" to advice from the news industry; and "Disrupting fake news economics" (Zuckerberg 2016b). ${ }^{4}$ We evaluate these solutions below.

\section{Elevate Quality of 'Related Articles' in News Feed}

In response to a question at SXSW about whether Facebook should reshuffle its algorithm to reduce filter bubbles, El-Sharawy (2017) states: "Facebook should take total responsibility - it is their problem - but I don't know what they should do." Prior to the fake news furore, earlier in 2016 Facebook was criticised by conservatives for using human editors to suppress conservative news stories in its Trending Topics. Initiating wider debates about Facebook's role in news distribution, journalists condemned Facebook for its absence of 
public mission in its commercial focus on giving users only what they found pleasing (Carlson 2017). Facebook's difficulty is that it needs to acknowledge that it is more than just a neutral pipes platform, but as explained earlier, it does not want to be accused of censorship. Nonetheless, since mid-December 2016, Facebook has been testing its algorithms to see if it can make fake news stories appear lower in its News Feed. Similarly, to combat the problem of Google ranking false news stories more highly than fact-checked true stories, as of March 2017 Google over-indexes fact-checked pieces to raise them artificially in the news feed (Bridges et al. 2017).

\section{Third-Party Verification by Fact-Checking Organisations and Stronger Technical Detection of Misinformation}

The fact-checking process finds claims that can be fact-checked; checks them (determining the best source to verify the fact); and rates them (evaluating whether evidence confirms or contradicts the claims). Following the 2016 election furore, Facebook teamed with several fact-checking websites, US international news agency Associated Press, and US broadcaster $A B C$ to flag-up to users if content seems potentially fake or deliberately misleading. These organisations have access to a proprietary dashboard showing them content flagged as fake news, plus other content flagged as suspicious by Facebook's algorithms. They decide what to debunk (for instance, suspicious stories getting maximum attention), marking the story as "disputed" when Facebook users attempt to share it (Mosseri 2016). Eric Carvin (Social Media Editor, Associated Press) hopes that, at minimum, this may make users feel embarrassed to share the story. The news organisations involved in fact-checking also write a debunk story (Bridges et al. 2017).

Experiments in automated fact-checking are also being conducted. Automation accelerates the fact-checking process and expands the audience quantity and type for factchecked news (Adair et al. 2017): expansion of audience type is important as typical conspiracy theory audiences are different to those who consume fact-checked news (Bounegru et al. 2017: 46). For instance, UK-based fact-checking organisation, Full Fact, is building statistics that finds patterns of claims, thereby producing data that can be used to train machine learning (Babakar and Moy 2016). In another experiment explained by Bill Adair (Knight Professor of Journalism and Public Policy, Duke University), Duke University's Share the Fact widget (developed with Google and JigSaw) identifies the person being fact-checked, the statement, conclusion and name of fact-checker, and visually creates a widget that goes in the fact-checking article and can be shared. This allows Google to recognise and highlight fact-checked articles while also creating a database of fact checks and a structure that can be used for voice search engines such as Amazon Echo (Adair et al. 2017).

While a promising avenue, fact-checking has problems. According to Alexios Mantzarlis (Director, International Fact-Checking Network/Poynter Institute), of the approximately 120 fact-checking organisations worldwide, most are charitable and face financial challenges, typically running on less than $\$ 100,000$ per year. Automated factchecking faces numerous obstacles. Mantzarlis points out that claims can be very nuanced, making them hard for a machine to evaluate. Mevan Babakar (Digital Products Manager, Full Fact) notes that the quality of open data can be problematic, as statistics change over time and between countries due to political and statistical reporting factors. Automated fact-checking also faces issues of biased human coders training the machines (Adair et al. 2017). A final, and perhaps most intractable, problem with fact-checking, whether done by people or bots, is that it assumes the user base prefers accuracy over content that feels right, reinforces their beliefs, or stimulates affective responses. 


\section{Warning Labels On Stories Flagged As False and Easier User Reporting Of Fake News}

Other strategies enacted by Facebook are placing warning labels on stories flagged as false; and easier user reporting of fake news. However, relying on users' ability to recognise fake news (to enable flagging and fact-checking) shifts responsibility from the fundamental problem: the economics underpinning the spread of fake news, and the propagandistic intentions of professional persuaders.

Even if users are seen as integral to solving the fake news problem, there are three psychological perception issues with the solution of flagging. Firstly, if people hear something a lot, they perceive it as true, even for facts that contradict prior knowledge (Fazio et al. 2015). Thus, as Lisa Fazio (Vanderbilt University) explains:

a second reading of something (for instance, a falsity) makes us more likely to think it is true. This makes it difficult when trying to dispute these false stories, as you don't want to repeat the false story to make it appear as true in people's heads (Bridges et al. 2017).

Secondly, people often forget the source of presented facts, including that they came from an unreliable source (Henkel and Mattson 2011). Fazio explains the consequences of this for flagging: "if a headline is marked false, we may remember the headline but not the false tag" (Bridges et al. 2017). A third problem is that prior beliefs influence how people remember corrected facts. This was demonstrated in the 2003 Iraq War, in studies on whether people remembered the wrong information or the correct information in inaccurate news that was subsequently corrected (Lewandowsky et al. 2005). Thus, flagging stories as false may not improve people's stock of correct knowledge (Bridges et al. 2017).

\section{Listen to Advice from the News Industry}

A further strategy proposed by Facebook is to listen to advice from the news industry, from which four types of innovation have been forthcoming.

Firstly, journalists have proposed tweaking algorithms on news sites to break people out of their filter bubbles by exposing them to material they would not normally choose, or that would not normally choose them. For instance, The Guardian's US website has a feature that shows five stories from conservative viewpoints that its readers would not have read (Wilson 2016). However, it is questionable how regularly breaking people out of their filter bubbles would be financially supported, especially if people refuse to engage with engineered material they did not want to see in the first place.

Secondly, some journalists are calling for increased transparency about their sources (John Bridges, Managing Editor, Austin American-Statesman). Bridges also notes the problem of journalists making honest mistakes in their initial reporting, but that social media rapidly turns these into a conspiracy theory: again, his proposed solution is increased journalistic transparency. However, this brings problems where opacity of sources is needed to bring truth to light (for instance, to encourage whistle-blowing).

A third innovation is to give people more direct interactions with their political representatives, to recalibrate what information they trust. For instance, the US app Countable breaks down news and legislative bills into simple English, and enables people to immediately communicate their position on any bill or issue with their lawmaker. Andrea Seabrook (Managing Editor, Countable) explains:

If we can get people to often and easily engage, then at the end of the political cycle, we will have decoupled people from the narrative that politicians will tell them what is 
the truth about the election. People will be able to see for themselves, by the time they next vote in 2018. (Seabrook and MacLaggan 2017)

However, such solutions, while potentially impactful in rebuilding engagement between politicians and voters, are nascent experiments. While they may encourage reporting on only what is actionable, there is no guarantee that this new format will be successful among users brought up on a fake news diet.

A fourth journalistic innovation is collaborative journalism to reduce the costs of factchecking. Responding to concerns about upcoming French elections in April and May 2017, First Draft created collaborative journalism project Cross Check, where French newsrooms check each other's accuracy. Running from February to May 2017, it allowed at least 17 French regional and international media companies to power a website where the public could report suspicious content, or ask questions for CrossCheck's media partners to respond to. Various data and tools were contributed by different media partners, including Facebook which supports the vetting platform through dedicated tools and media literacy efforts to explain the verification process and keep audiences updated with confirmed and disputed election information (Bridges et al. 2017). That forthcoming elections have been singled out as needing this sort of initiative is no doubt a response to the rising tide of populism across Europe. Whether initiatives such as Cross Check will be deployed for all elections remains to be seen. This would require demonstration of its efficacy, as well as continued political and commercial will to improve journalism's accuracy at politically decisive moments.

\section{Disrupt Fake News Economics}

A little-discussed solution proposed by Facebook is disrupting fake news economics. Since the 2016 US presidential elections Facebook has eliminated the ability to spoof domains to reduce the prevalence of sites masquerading as well-known news organisations (Mosseri 2016). However, we suggest that closer attention should also be paid to digital advertising. Perhaps unsurprisingly given its business model, Facebook has said little on this solution, and it was barely addressed at SXSW in 2017, despite multiple industry panels on fake news. It is to this solution that we now turn.

\section{Media Economics and Digital Advertising: A Solution Lies Within the Problem}

Rather than simply relying on social networking sites to find the "right" algorithm while negotiating censorship accusations; on Facebook users to exercise rational judgement in recognising, flagging and sharing fake news; and on resource-poor journalists to experiment with breaking people out of their filter bubbles while committing to fact-checking; we suggest that the role of digital advertisers in proliferating fake news also needs scrutiny. After all, many of the fake news websites of the 2016 US presidential election were ultimately created not for propaganda, but for money.

\section{Digital Advertising Enables Fake News Sites to Profit}

There is a longstanding relationship between the press and its need for advertising revenue. Underpinning this is the fiscal value of audience attention, as the rates that publishers charge advertisers depend upon the size and nature of the audience they can deliver. Unfortunately, as explained earlier, the societal shift towards digital media, and its economic model, has not favoured legacy news organisations. Conversely, the new economic underpinnings enable fake news sites to flourish.

It is the way digital advertising is paid for and served that favours fake news sites. Whereas in print news, advertisers and agencies working on their behalf carefully choose their 
news outlet, advert format and whether an adjacent story might damage a brand, such consideration is often not possible online because of the nature of online behavioural advertising. While advertisers may buy direct from an online news publisher, behavioural targeting techniques are more commonly used. This is the practice of tracking people's online behaviour and serving them advertisements on the basis of what they do online. The principle behind behavioural targeting is that it targets the person rather than the publication. Furthermore, while advertising spaces are ultimately owned by the web publisher, they are effectively outsourced and rented to entities called 'ad networks' (namely, businesses that sit between web publishers and organisations wishing to advertise) (see Figure 1).

\section{Figure 1 Advertising Networks' Place in Business Chain}
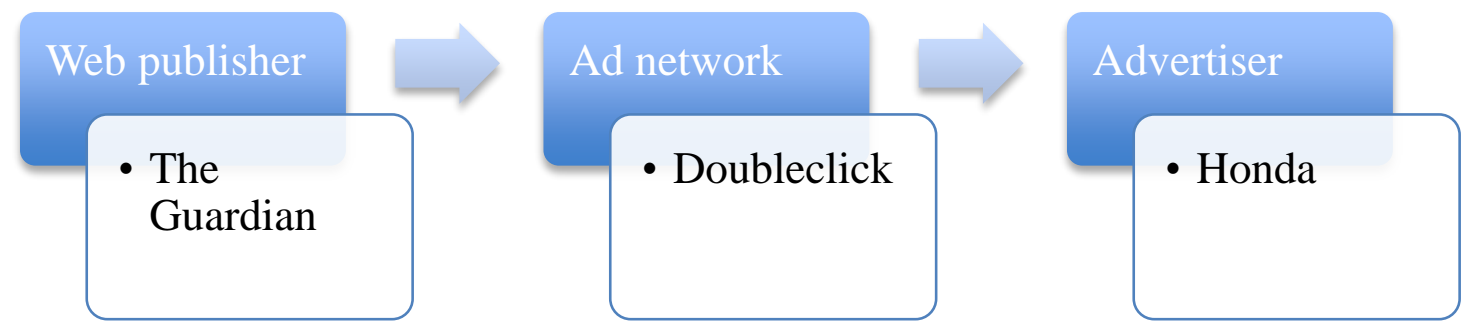

Ad networks (such as Doubleclick) are thus able to offer advertisers a massive range of websites to exhibit their ads, allowing them to reach potentially large, but also profiled, audiences. For sense of scale, Google's Doubleclick ad network spans over two million websites that reach over $90 \%$ of people on the internet. Small and large publishers alike benefit because ad networks give publishers a way to profit from their advertising spaces without having to go to the effort of selling individual slots to advertisers.

On top of this, programmatic techniques (called 'programmatic' by the advertising industry) allow additional data to be used to further target the advertising. Programmatic allows advertisers to target consumers automatically based on certain metrics obtained through algorithms. It differs from behavioural advertising in that it draws on a wider variety of sources than data from ad networks to target audiences (such as first-party data from the brand advertising or third-party data about potential audiences). It also provides opportunity to use automated means to create (as well as target) advertising: information about the audience can be used to personalise the design of advertising for identified audiences.

Critical to our concern with fake news is that although advertising served by ad networks maximises an advertisement's reach to whom-so-ever and wherever a desirable person might be, advertisers relinquish control over where their advertising is displayed. Such automation of the ad space buying process has resulted in advertisers having less understanding of the websites and pages they are appearing on. Indeed, adverts for brands such as Honda, Thomson Reuters, Halifax, Argos, John Lewis, Disney and the Victoria and Albert Museum have appeared on content promoting Islamic State (ISIS) and neo-Nazi content. This is because the behavioural and programmatic advertising profiles the person rather than the website they are looking at. Similarly, if the user looks at a fake news site, the adverts will appear there.

\section{Publishers \\ Follow the Money: Engage Digital Advertising Industry to Identify Fake News}

However, advertisers - even the most disreputable - are unlikely to want their advertising associated with content that, by its very nature (that is, fake news), cannot be trusted. The issue of brand safety is an ongoing one within the digital advertising industry, 
and the contemporary issue of online fake news adds political and public impetus to resolve this. Advertising firms are well placed to identify suspected fake news publishers. Several ad networks and programmatic companies already promise that they can deliver brand-safe adverts. Rubicon, for example, claims it can identify undesirable publishers before the advertisements are released, and can track activity during and after the campaign to see who clicked on which advertisements and where. The Wall Street Journal reported on 14 November 2016 that Google Adsense had already begun blocking sites. However, to be effective, all the ad networks need to be involved to prevent fake news sites that have been ejected from one ad network from simply moving to another, as currently happens (Bounegru et al. 2017, Silverman et al. 2017).

As such, to tackle the fake news problem at its economic heart, we recommend that governments consult with self-regulatory bodies that represent ad networks, advertising agencies and advertisers (for example, Internet Advertising Bureau and International Advertising Association). The possibility here is twofold in that: (1) governments can pressurise advertising associations that largely enjoy self-regulatory status; and (2) advertising associations are well placed to educate their members, especially advertisers. Given that the advertising chain requires publishers, ad networks and advertisers to function, if advertisers place financial pressure on the system, there is scope to reduce the income of both fake news publishers and the ad networks that host them. For instance, on clicking on fake news website "abcnews.com.co" with the Ghostery add-on, it reveals two active ad networks: Viglink ${ }^{5}$ and ShareThis ${ }^{6}$. Both consider themselves to be respectable companies: Viglink has venture capital backing from Google; and ShareThis has funding from leading venture capital firms (such as Draper Fisher Jurvetson) and is already connected to the Digital Advertising Alliance, which is an association that claims to promote responsible privacy practices. In general, these ad networks are not outliers, but seek to lead, and be part of, the mainstream advertising community. Pressure can be applied on these to be more discriminating.

There is merit in the point of Silverman et al. (2017) that if fake news sites are rejected by mainstream ad networks, they will eventually gravitate to less discriminating ones. However, we posit that with greater transparency in the system for advertisers, non-fake news publishers and advertisers are likely (or can be encouraged) to stop using the less discriminating ad network. This would eventually leave less discriminating ad networks with mostly low-quality advertisers (of Viagra, for example) who may only care about the likelihood of click-throughs. Furthermore, the very presence of such advertised products would help citizens identify the site as fake and untrustworthy. Also, given that ad networks benefit from economies of scale, the departure of reputable advertisers and publishers would be harmful and possibly terminal to that ad network.

Next, if modern programmatic advertising promises greater control over the campaign management process, we recommend that the advertising industry be tested on this, starting with fake news websites. Again, this may be overseen and reviewed by a working group of trade associations and a dedicated governmental committee, with minutes and outcomes published for the press and interested citizens. To conclude, we do not suggest that targeting behavioural advertising is a silver bullet solution, but rather that it is a meaningful step in choking revenue for fake news.

\section{The Near-Horizon: Automated Fake News and Manipulation of Fellow-Feeling}

Given the rapid onset, scale and nature of the contemporary fake news problem, it is important to consider near-future possibilities. In the context of fake news, this includes the ability to manipulate public sentiment via automated fake news. This distinct possibility arises because the success of fake news comes from its creators having financial self-interest in 
"feeling-into" online conversations and creating headlines to resonate with specific groups (such as pro-Trump supporters). There is a clear and relatively simple opportunity to marry technology that detects online emotion via the language and words that individual and groups post, with automated news, namely news headlines and body copy written by computers.

\section{Understanding and Knowing How to Manipulate Public Moods}

Fake news creators are already "feeling-into", and profiting from, collectives from afar. For instance, Macedonian fake news providers exploit the beliefs, desires and concerns of specific US audiences. They can do this because online social media communities (such as on Facebook) already encourage echo chambers to form, be this via filter bubbles, confirmation bias or both. Earlier, we noted the rise of "empathic media" (McStay 2016b) - namely, technologies that gauge emotions, intentions and life contexts to maximise appropriateness of feedback and content. Of most relevance to our concerns with fake news is analysis of emotions in words and images. Such sentiment analysis is widely used to search and crossreference social media data and news articles for insights into social feeling towards a given issue that would be valuable to a client organisation (such as marketers).

The next step from understanding public moods is knowing how to manipulate them. A well-known example is the 2014 Facebook study on emotional contagion. Without participant consent, researchers secretly optimised 689,003 people's news feeds: they found that when exposed to stimuli with positive or negative emotional content, people within social networks tend to replicate this in their own posting behaviour. The study's authors conclude that this provides "experimental evidence for massive-scale contagion via social networks" (Kramer et al. 2014: 8788). In other words, the study demonstrated the ability to calculate publics and algorithmically sort and manipulate online fellow-feeling.

\section{The Move Towards Automated News: Algo-journalism}

Facebook's emotional contagion study shows that exposure to a particular type of affective content in users' news feeds stimulates posting behaviour that reflects the emotional charge of that content. When we consider this principle in light of news-based filter bubbles, it is reasonable to posit a positive feedback loop that amplifies an affective tone. Fake news already represents an increase in emotional charge, but automated news has the potential to intensify this situation.

Automated journalism (or "algo-journalism") is increasingly used by legacy news agencies such as Associated Press to provide detail-heavy news that does not require (expensive) human interpretation or analysis (McStay 2016a). Algo-journalism is typically used to distil and report key features of complex texts such as investment holdings, billing records and sports statistics, with data storytelling provided by companies such as IBM Watson and Narrative Science. In 2016, The Washington Post experimented with software bots to generate more insightful stories with a stronger editorial voice on stories about election wins and electoral trends. These work by editors creating narrative templates and stock key phrases that account for various potential outcomes which the software bot then matches and merges with structured data - in the case of the US election, via data clearinghouse VoteSmart.org, but also "Associated Press data, historic data and polling" (Andrews et al. 2017). Given how simple fake news storylines are compared to election coverage, there is no reason why fake news stories could not be generated by algojournalism.

Automated Insights also create automated journalism, although algorithmically rather than template-based. Joe Procopio (Chief Innovation Officer Automated Insights) explains that algorithms "determine the tone [our emphasis]. It gives us insights as to what the most important part of the story is. ... We do all this algorithmically to get the reader the most 
important things they need from that story" (Andrews et al. 2017). Other users of algojournalism are the Norwegian News Agency. While currently using it to deliver coverage of local sports fixtures that otherwise would go unreported, the news agency envisions that it would use algo-journalism for any repetitive stories that use regularly updated data. According to Helen Vogt (Director of Product Development, Norwegian News Agency), algojournalism can automatically use data to tailor the story for local audiences (Andrews et al. 2017). Thus, the ability to automatically enable tone-optimised and geo-tailored stories is already at hand - both practices that fake news creators would find helpful.

As well as automatically generating fake news storylines with a strong editorial voice, tone-optimised and geo-tailored for specific audiences, software bots could be used to widely spread such automated fake news, thereby giving the impression that the fake news is popular and endorsed by many (a 2016 survey of 26 countries finds that most people share predominantly news of which they approve (Reuters Institute 2016)). This is not a dystopian fantasy: during the 2010 US midterm elections and Massachusetts special election, social bots were employed to support some candidates and smear their opponents, injecting thousands of tweets pointing to websites with fake news (Ratkiewicz et al. 2011; Metaxas and Mustafaraj 2012).

\section{The Potential for Empathically-optimised Automated Fake News}

Contemporary fake news already operates in the context of "feeling-into" online collectives, filter bubbles, confirmation bias and echo chambers. The opportunity for computer generated fake news, weaponised and optimised to resonate with social media users, seems entirely feasible given the current state of sentiment analysis and automated journalism, as well as the affective tenor of the Trump presidential campaign. The process would be to: understand key trigger words and images among target groups; create fake news, and measure its engagement (via click-throughs, shares, likes and effectiveness of message elements); and then have machines learn in an evolutionary capacity from this experience to create stories with more potency to increase engagement and thereafter advertising revenue. The feedback process also has implications for use of aggressive propaganda and information wars (at the time of writing, US journalism and US senate intelligence inquiries were concerned about Russia's attempts to influence elections abroad, including the USA and Europe). We suggest that the commercial and political phenomenon of empathicallyoptimised automated fake news is on the near-horizon.

\section{Conclusion}

Fake news is not a new phenomenon, but the 2016 US presidential election showed us a new iteration, driven by profit and exploited by professional persuaders. While a laudable variety of solutions to the deeply socially and democratically problematic contemporary fake news phenomenon have been proposed, each faces specific obstacles to achieving widespread implementation and impact. While we recognise the need for all these solutions to take root, our recommendation, to focus on digital advertising, addresses the contemporary phenomenon at its economic heart. As such, we suggest that policy-makers and regulators take immediate steps to consult with international trade associations representing advertising, large advertisers, ad networks and programmatic firms. While not a silver-bullet solution, advertisers have a self-interest in a healthier advertising media environment because even the most disreputable will not want their adverts associated with content that cannot be trusted (fake news). By focusing on the economic dimension, this also guards against the nearhorizon possibility of empathically-optimised automated fake news, as a large driver of the fake news phenomenon is economically motivated. Again, to pre-empt this, governments should invite to the conversation analytics companies from the growing empathic media 
sector, such as IBM, Cambridge Analytica, Crimson Hexagon and Narrative Science to discuss the growth of micro-targeted empathically-optimised automated fake news. With diverse international political actors waging information war, an educated and strong economic counter-attack may be the best defence.

\section{References}

Adair, Bill, Mevan Babakar, Chengkai Li, and Alexios Mantzarlis. 2017. "How Bots Are Automating Fact-Checking." Panel at SXSW Interactive, Austin, Texas, March 10-16.

Ackerman, Spencer. 2017. "Russian Deception Influenced Election due to Trump's Support, Senators Hear.” The Guardian, March 30. https://www.theguardian.com/usnews/2017/mar/30/trump-russia-fake-news-senate-intelligence-committee

Allcott, Hunt and Matthew Gentzkow. 2017. "Social Media and Fake News in the 2016 Election." https://web.stanford.edu/ gentzkow/research/fakenews.pdf

Andrews, Wilson, Jeremy Gilbert, Joe Procopio, and Helen Vogt. 2017. "Future of Automated News: 2016 Election and Beyond." Panel at SXSW Interactive, Austin, Texas, March 10-16.

Babakar, Mevan and Will Moy. 2016. "The State of Automated Factchecking.” Full Fact. https://fullfact.org/media/uploads/full_factthe_state_of_automated_factchecking_aug_2016.pdf

Bakir, Vian and Andrew McStay. 2017. "Combatting Fake News: Analysis of Submissions to the Fake News Inquiry." Three-D 28. https://www.meccsa.org.uk/news/three-d-issue-28combatting-fake-news-analysis-of-submissions-to-the-fake-news-inquiry/.

Berkowitz, Dan and David A. Schwartz. 2016. "Miley, CNN and The Onion." Journalism Practice 10(1): 1-17, doi:10.1080/17512786.2015.1006933.

Bessi Alessandro, Fabiana Zollo, Michela Del Vicario, Michelangelo Puliga, Antonio Scala, and Guido Caldarelli. 2016. "Users Polarization on Facebook and Youtube." PLoS ONE 11(8): e0159641. doi:10.1371/journal.pone.0159641.

Bounegru, Liliana, Jonathan Gray, Tommaso Venturini, and Michele Mauri. 2017. “A Field Guide to Fake News." Public Data Lab.

http://fakenews.publicdatalab.org/download/SAMPLE-field-guide-to-fake-news.pdf

Breitbart. 2016a. Facebook Timeline Photos, October 10.

https://www.facebook.com/Breitbart/photos/a.10152968700630354.1073741830.9547502035 3/10157873843625354/?type $=3 \&$ theater

Breitbart. 2016b. Facebook Timeline Photos, October 16.

https://www.facebook.com/Breitbart/photos/a.10152968700630354.1073741830.9547502035 3/10157911561890354/?type $=3 \&$ theater

Breitbart. 2016c. Facebook Timeline Photos, October 20.

https://www.facebook.com/Breitbart/photos/a.10152968700630354.1073741830.9547502035 3/10157933056590354/?type=3\&theater

Breitbart. 2016d. Facebook Timeline Photos, October 20.

https://www.facebook.com/Breitbart/photos/a.10152968700630354.1073741830.9547502035 3/10157932892060354/?type=3\&theater

Breitbart. 2016e. Facebook Timeline Photos, October 28.

https://www.facebook.com/Breitbart/photos/a.10152968700630354.1073741830.9547502035 3/10157981281375354/?type $=3 \&$ theater

Bridges, John, Eric Carvin, Lisa Fazio, and Claire Wardle. 2017. "A Post-Truth World? Nope - We Can Fight Fake News." Panel at SXSW Interactive, Austin, Texas, March 10-16.

Carlson, Matt. 2017. "Facebook in the News." Digital Journalism. doi: 


\subsection{0/21670811.2017.1298044.}

Charity Watch. 2016. "Clinton Foundation.” https://www.charitywatch.org/ratings-andmetrics/bill-hillary-chelsea-clinton-foundation/478

Culture, Media and Sport Committee. 2017. “"Fake News' Inquiry.” UK Parliament. https://www.parliament.uk/business/committees/committees-a-z/commons-select/culturemedia-and-sport-committee/inquiries/parliament-2015/inquiry2/

Datu, Cherisse, Kelli Dunlap, Grace Lindsay, and Joyce Rice. 2017. "Engineered Collisions Between Games and News." Panel at SXSW Interactive, Austin, Texas, March 1016.

El-Sharawy, Steve. 2016. "Donald Trump as President? Thank Facebook." EzyInsights, November 1. https://ezyinsights.com/blog/2016/11/01/donald-trump-as-president-thankfacebook/

El-Sharawy, Steve. 2017. "With Extreme Bias: Consuming Media in the Trump Era." Paper presented at SXSW Interactive, Austin, Texas, March 10-16.

Fazio, Lisa K., Nadia M.Brashier, B.Keith Payne, and Elizabeth J. Marsh. 2015. "Knowledge Does Not Protect Against Illusory Truth." Journal of Experimental Psychology 144(5): 993-1002. http://dx.doi.org/10.1037/xge0000098

Gillin, Joshua. 2017. "Fact-checking Fake News Reveals how Hard it is to Kill Pervasive 'Nasty Weed' Online.” Punditfact, January 27.

http://www.politifact.com/punditfact/article/2017/jan/27/fact-checking-fake-news-revealshow-hard-it-kill-p/?

Gillmor, Dan. 2009. “Toward a Slow-News Movement.” Mediactive. http://mediactive.com/2009/11/08/toward-a-slow-news-movement/

Habermas, Jurgen. 1984. The Theory of Communicative Action, Volume 1: Reason and the Rationalization of Society. trans. by Thomas McCarthy, Boston: Beacon Press.

Henkel, Linda A. and Mark E.Mattson. 2011. "Reading is Believing: The Truth Effect and Source Credibility." Consciousness and Cognition 20: 1705-1721. doi:10.1016/j.concog.2011.08.018.

Jackson, Dan and Kevin Moloney. 2016. "Inside Churnalism: PR, Journalism and Power Relationships in Flux.” Journalism Studies 17(6): 763-780. doi:10.1080/1461670X.2015.1017597

Jowett, Garth S. and Victoria J. O'Donnell. 2012. Propaganda and Persuasion, 5th edn. London: Sage.

Khaldarova, Irina and Mervi Pantti. 2016. "Fake News." Journalism Practice 10(7): 891-901. doi:10.1080/17512786.2016.1163237.

Kirby, Emma Jane. 2016. "The City getting Rich from Fake News." BBC News, December 5. http://www.bbc.co.uk/news/magazine-38168281

Kramer, Adam D. I., Jamie E. Guillory and Jeffrey T. Hancock. 2014. "Experimental Evidence of Massive-scale Emotional Contagion through Social Networks." Proceedings of the National Academy of Sciences of the United States of America 111(24): 8788-8790. doi: 10.1073/pnas.1320040111.

Leveson Inquiry. 2012. "Report into the Culture, Practices and Ethics of the Press." Department for Culture, Media and Sport. https://www.gov.uk/government/publications/leveson-inquiry-report-into-the-culturepractices-and-ethics-of-the-press

Lewandowsky, Stephan, Werner G.K. Stritzke, Klaus Oberauer, and Michael Morales. 2005. "Memory for Fact, Fiction, and Misinformation: The Iraq War 2003." Psychological Science 16(3): 190-195. http://dx.doi.org/10.1111/j.0956-7976.2005.00802.x 
Marchi, Regina. 2012. "With Facebook, Blogs, and Fake News, Teens Reject Journalistic 'Objectivity'." Journal of Communication Inquiry 36(3): 246-262. doi: 10.1177/0196859912458700.

McStay, Andrew. 2016a. Digital Advertising (Second Ed.). London: PalgraveMacmillan.

McStay, Andrew. 2016b. "Empathic Media and Advertising: Industry, Policy, Legal and Citizen Perspectives (the Case for Intimacy)". Big Data \& Society, 3(2): 1-11. doi: $10.1177 / 2053951716666868$

McStay, Andrew. 2017. Privacy and the Media. London: Sage.

McStay, Andrew. (in preparation, 2018). Emotion AI: The Rise of Empathic Media. London: Sage.

Metaxas, Panagiotis T. and Eni Mustafaraj. 2012. "Social Media and the Elections." Science 338(6106): 472-473. doi:10.1126/science.1230456.

Miles, Matthew B., A.Michael Huberman, and Johnny Saldana. 2014. Qualitative Data Analysis. London: Sage.

Miller, David and William Dinan. 2008. A Century of Spin: How Public Relations Became the Cutting Edge of Corporate Power. London: Pluto Press

Moloney, Kevin. 2006. Rethinking Public Relations. $2^{\text {nd }}$ ed. London: Routledge.

Mosseri, Adam. 2016. "News Feed FYI: Addressing Hoaxes and Fake News." Facebook, December 15. https://newsroom.fb.com/news/2016/12/news-feed-fyi-addressinghoaxes-and-fake-news/

Mouffe, Chantal. 2005. On the Political. London: Routledge.

Pariser, Eli. 2011. The Filter Bubble: What the Internet Is Hiding from You. New York: Penguin Press.

Pew Research Center. 2016. "State of the News Media 2016." http://www.journalism.org/2016/06/15/state-of-the-news-media-2016/

Powers, Elia. 2017. "My News Feed is Filtered?" Digital Journalism. doi: 10.1080/21670811.2017.1286943.

Price, Rob. 2016. “A Report that Fake News 'Outperformed' Real News on Facebook suggests the Problem is Wildly out of Control." Business Insider, 17 November. http://uk.businessinsider.com/fake-news-outperformed-real-news-on-facebook-before-uselection-report-2016-11?r=DE\&IR=T

Quattrociocchi, Walter, Antonio Scala, and Cass R. Sunstein. 2016. "Echo Chambers on Facebook." SSRN. https://papers.ssrn.com/sol3/papers.cfm?abstract_id=2795110

Ratkiewicz, Jacob, Michael D.Conover, Mark, Meiss, Bruno Goncalves, Alessandro Flammini, and Filippo Menczer. 2011. "Detecting and Tracking Political Abuse in Social Media." In 5th International AAAI Conference on Weblogs and Social Media: 297-304. http://www.aaai.org/ocs/index.php/ICWSM/ICWSM11/paper/view/2850

Reuters Institute. 2016. "Digital News Report." http://reutersinstitute.politics.ox.ac.uk/sites/default/files/Digital-News-Report-2016.pdf

Richards, Barry. 2007. Emotional Governance: Politics, Media and Terror. Houndsmill: Palgrave MacMillan.

Scammell, Margaret. 2014. Consumer Democracy: The Marketing of Politics. New York: Cambridge University Press.

Schweizer, Peter. 2015. Clinton Cash. New York: Harper.

Seabrook, Andrea and Corrie MacLaggan. 2017. "Making News Actionable." Panel at SXSW Interactive, Austin, Texas, March 10-16.

Silverman, Craig. 2016. "This Analysis shows how Viral Fake Election News Stories Outperformed Real News on Facebook.” BuzzFeed News, November 16. 
https://www.buzzfeed.com/craigsilverman/viral-fake-election-news-outperformed-real-newson-facebook?

Silverman, Craig and Lawrence Alexander. 2016. "How Teens in The Balkans are Duping Trump Supporters with Fake News." BuzzFeed News, November 4.

https://www.buzzfeed.com/craigsilverman/how-macedonia-became-a-global-hub-for-protrump-misinfo?

Silverman, Craig, Jeremy Singer-Vine, and Lam Thuy Vo. 2017. "In Spite Of The Crackdown, Fake News Publishers Are Still Earning Money From Major Ad Networks." BuzzFeed News, April 4. https://www.buzzfeed.com/craigsilverman/fake-news-real-ads?

Stanford History Education Group. 2016. "Evaluating Information: The Cornerstone of Civic Online Reasoning."

https://sheg.stanford.edu/upload/V3LessonPlans/Executive\%20Summary\%2011.21.16.pdf

Suler, John. 2016. Psychology of the Digital Age: Humans Become Electric. New York: Cambridge University Press.

Sunstein, Cass. 2001. Echo Chambers: Bush Vs. Gore, Impeachment, and Beyond. Princeton, N.J: Princeton University Press.

Tynan, Dan. 2016. "How Facebook Powers Money Machines for Obscure Political 'News' Sites." The Guardian, August 24.

https://www.theguardian.com/technology/2016/aug/24/facebook-clickbait-political-newssites-us-election-trump

Wardle, Claire. 2017. "Fake News. It's Complicated." First Draft. https://medium.com/1st-draft/fake-news-its-complicated-d0f773766c79

Wason, P.C. 1960. "On the Failure to Eliminate Hypotheses in a Conceptual Task." Quarterly Journal of Experimental Psychology 12(3): 129-140. doi:10.1080/17470216008416717.

Wilson, Jason. 2016. "Burst your Bubble: Five Conservative Articles to Read before 2016 Ends." The Guardian, 30 December. https://www.theguardian.com/usnews/2016/dec/30/conservative-liberal-news-filter-bubble

Zuckerberg, Mark. 2016a. 'Mark Zuckerberg.' Facebook, November 13. https://www.facebook.com/zuck/posts/10103253901916271

Zuckerberg, Mark. 2016b. 'Mark Zuckerberg.' Facebook, November 19. https://www.facebook.com/zuck/posts/10103269806149061

\footnotetext{
${ }^{1}$ While the calling of a UK General Election for June 2017 meant that the Fake News Inquiry closed before synthesising and making recommendations on its 78 written submissions, we have evaluated these elsewhere (Bakir and McStay 2017), reaching the same conclusion as in this paper.

${ }^{2}$ Available at:

https://www.facebook.com/pg/Breitbart/photos/?tab=album\&album_id=10152968700630354

${ }^{3} \mathrm{http}: / /$ factitious.augamestudio.com/\#/

${ }^{4}$ Facebook also presented these solutions to the Fake News Inquiry: http://data.parliament.uk/writtenevidence/committeeevidence.svc/evidencedocument/culture-mediaand-sport-committee/fake-news/written/49394.html

${ }^{5}$ See Viglink: http://www.viglink.com/about/

${ }^{6}$ See ShareThis: https://www.sharethis.com/about/
} 